\title{
The critical effect of subgrid-scale scheme on simulating the climate impacts of deforestation
}

Dashan Wang ${ }^{1}$, Jie Wu ${ }^{1,2}$, Maoyi Huang ${ }^{3}$, Laurent Z. X. Li $^{4}$, Dagang Wang ${ }^{5}$, Ting Lin ${ }^{6}$, Li Dong ${ }^{6}$, Qi Li ${ }^{7}$, Long Yang ${ }^{8}$, Zhenzhong Zeng ${ }^{*}$

\author{
Affiliations: \\ ${ }^{1}$ School of Environmental Science and Engineering, Southern University of Science and \\ Technology, Shenzhen, China \\ ${ }^{2}$ Department of Geoscience and Natural Resource Management, University of Copenhagen, \\ Copenhagen, Denmark \\ ${ }^{3}$ Atmospheric Sciences and Global Change Division, Pacific Northwest National Laboratory, \\ Richland, WA, USA \\ ${ }^{4}$ Laboratoire de Météorologie Dynamique, Le Centre National de la Recherche Scientifique, \\ Sorbonne Université, Ecole Normale Supérieure, Ecole Polytechnique, Paris, France \\ ${ }^{5}$ School of Geography and Planning, Sun Yat-sen University, Guangzhou, China \\ ${ }^{6}$ Department of Earth and Space Science, Southern University of Science and Technology, \\ Shenzhen, China \\ ${ }^{7}$ School of Civil and Environmental Engineering, Cornell University, Ithaca, NY, USA \\ ${ }^{8}$ School of Geography and Ocean Science, Nanjing University, Nanjing, China \\ *Correspondence to: zengzz@sustech.edu.cn
}

\section{Key Points:}

- Employing land surface schemes that take a sub-grid approach is critical in simulating the climate impacts of fine-scale land cover change

- Land surface schemes that take a dominant approach can largely misestimate the climate response to land cover change

- The theoretical tiling approach of CLM was not active when it was coupled into the Weather Research and Forecasting model 


\begin{abstract}
Land surface schemes in Earth System Models simulate how vegetation regulates land-atmosphere fluxes of heat, water, carbon, and momentum. Despite the spatial resolution of regional climate modelling that we can reach now has advanced, many land cover changes still occur at sub-grid scale, and need to be properly treated. Here, we investigate the response of evapotranspiration, representing the fluxes of heat and water, to deforestation in Southeast Asian Massif by employing three land surface schemes (Noah mosaic, Noah-MP and Community Land Model (CLM)) with different approaches in representing sub-grid variability, implemented in the Weather Research and Forecasting model. Two experiments, with and without satellite-observed deforestation, were performed for each scheme. Results show that the simulations are highly sensitive to the subgrid-scale approaches embedded in the land surface schemes. Comparing to the observed historical climate, CLM outperforms others and Noah mosaic shows the largest bias. However, if we target the simulation of the climate impacts of land cover change, the Noah mosaic scheme which takes the sub-grid approach can better capture the response of evapotranspiration to deforestation. The NoahMP and CLM schemes underestimate the evapotranspiration response in the grid cells where the dominant land cover type has not changed, but they overestimate the response in those grid cells with dominant type changed, which is a characteristic of dominant-grid approach. To improve our understanding of climate impacts induced by fine-scale land cover change, future efforts to better represent subgrid-scale variability and land-atmosphere flux exchange in climate models are desirable.
\end{abstract}

Keywords: subgrid-scale variability; land cover change; climate response; land surface schemes; coupled model 


\section{Introduction}

The realistic representation of land surface processes is still a challenge in Earth system modeling (Betts, 2009). On the one hand, the nonlinear nature of land-atmosphere interaction calls for accurate description of land surface characteristics and biogeophysical processes in models (Mallard \& Spero, 2019). This relies on appropriate parameterizations to reproduce the vegetative and radiative properties of the surface reasonably (Yano, 2016; Tomasi et al., 2017). On the other hand, land surface properties exhibit high degree of spatial heterogeneity (Sellers, 1991). Although advances in technology, such as multi-source remote sensing, could yield land surface information in fine resolutions $(\leq 5 \mathrm{~m})$, Earth system models and numerical weather models are typically implemented at coarser grid spacing ranging from a few hundreds of $\mathrm{km}$ at global scale to a few kilometers at regional scale. Land cover parameters can vary significantly within a model mesh, affecting the mean surface fluxes at the grid level and climate dynamics at larger scales ( $\mathrm{Li}$ et al., 2013). As such, subgrid-scale variability, indicating the heterogeneous properties of land surface, is substantial in Earth system modeling and should be attached great importance.

In the past few decades, different strategies of physical parameterization have been employed to integrate land surface information in models (Giorgi \& Avissar, 1997). As one of the most common method, the "dominant" approach provides parameters of the most abundant land cover type (LCT) within each grid cell, and the state characteristics and processes are assumed to be uniform (Noilhan \& Planton, 1989; Chen et al., 1997). Generally, this approach is a trade-off between considering the model complexity in a simple way and omitting the representation of subgrid-scale interactions and processes. There are several approaches deliberating the subgrid-scale variability. One is the "composite" approach (Koster \& Suarez, 1992), which aggregates parameter values of all LCTs within a grid cell into one homogeneous but fictitious type. Another is the "statistical-dynamical" approach (Avissar, 1991), in which parameters within a grid cell are divided into a number of bins following probability density functions, and the fluxes are computed using the bin values of surface parameters. Different from the former two methods, the "mosaic/tiling" approach provides a more realistic way (Avissar \& Pielke 1989; Li et al., 2013). The grid cell is divided into a certain number of tiles based on LCTs, and the surface is assumed to be homogeneous and continuous in each tile. Then the fluxes of water and energy, as well as other state variables that characterize surface, are calculated within each tile independently. The output values of all tiles are spatially aggregated by a certain rule to obtain the values of the grid cell.

The Weather Research and Forecasting (WRF) model (Skamarock et al., 2019) is a powerful tool in simulating the regional climate and land-atmosphere interactions due to its sophisticated mesoscale and three-dimensional dynamical downscaling structure. Within the WRF model, the land surface scheme (LSS) regulates the fluxes of heat, water vapor and momentum between land and atmosphere (Ek et al., 2003). WRF has been coupled with several land surface schemes. Because of the nonlinear interaction processes involved, different LSSs vary in parameterizations and representations of subgrid-scale variability. Many studies have performed contrast experiments in different LSSs (Chen et al., 2014; Liu et al., 2019; Ma et al., 2020) or various land surface parameters (Li et al., 2014; Georgescu, 2015) were used with shared same model dynamical and physical options to simulate regional climate. Both model users and developers can benefit from these strategies: users select suitable schemes or 
parameter settings in their particular studies; developers improve the model structures, parameterizations and algorithms. However, better performance for a certain scheme in historical climate simulations does not mean this scheme can also reasonably capture the climate response to land cover change. Even sporadic changes in land cover could enhance heterogeneities in land surface characteristics. Model sensitivity to subgrid-level land cover change varies among LSSs. This implies that, the effect of subgrid-scale variability in modeling climate feedbacks of land cover changes needs to be critically assessed, especially for those local but intensive changes (Bou-Zeid et al., 2020).

During the past two decades, Southeast Asian Massif (SAM) has undergone rapid and fragmental agriculturally-driven forest loss, especially in the mountainous areas, providing an ideal test bed for this study (Zeng et al., 2018; Hansen et al., 2020). Previous work showed that surface characteristics, such as leaf area index (LAI), albedo and roughness, over deforested areas differ substantially from those in forested areas, therefore lead to local-scale biogeophysical feedbacks (Mahmood et al., 2013; Lawrence \& Vandecar, 2015; Alkama \& Cescatti, 2016). As a crucial process in the climate feedback of forest loss, evapotranspiration affects the exchanges of water and energy between land and atmosphere (Bonan, 2008; Jung et al., 2010). In the SAM, deforestation causes lower evapotranspiration-induced warming and higher albedo-induced cooling, leading to an overall local warming that is dominated by the decrease in evapotranspiration (Zeng et al., 2021). However, to our knowledge, research that addressed the importance of subgrid-scale variability of LSSs in simulating the climate impacts of deforestation is limited. In this study, we created a deforestation scenario based on highquality satellite-based forest cover products and ingested it into the WRF model, and compared the WRF simulations with and without deforestation over the SAM. The sensitivity of evapotranspiration in response to forest loss of different LSSs were investigated by comparing the results of simulations under two scenarios. We focused on the sensitivity of evapotranspiration because it directly represents the changes in land-atmosphere fluxes of both heat and water.

\section{Materials and methods}

\subsection{WRF land surface schemes}

The WRF model with the Advanced Research WRF (ARW) dynamical core (version 4.1.2) was employed in this study. Here we focused on three widely used LSSs that vary in subgridscale approaches, namely, the Noah model using the mosaic approach (hereafter Noah mosaic), the community Noah land surface model with multi-physics parameterization options (NoahMP), and the Community Land Model version 4 (CLM4). The Noah mosaic scheme (Li et al., 2013; added in WRF version 3.6) is rooted in the Noah scheme (Chen \& Dudhia, 2001). Different from the Noah scheme that employs a "dominant" approach at the grid scale, Noah mosaic allows users to take the heterogeneous land cover into account by specifying certain number $(N)$ of tiles in each grid cell. The most abundant $N$ types of land cover within each grid are considered in the subgrid-scale calculation of surface state variables and fluxes, which are then aggregated to grid averages. The Noah-MP scheme (Niu et al., 2011; Yang et al., 2011; added in WRF version 3.4) is an advanced version of the Noah scheme. It contains more sophisticated model structure, including separated vegetation canopy and surface layers, a modified two-stream radiation transfer scheme, updated soil and groundwater hydrological processes, and a dynamic vegetation option. Similar to Noah, Noah-MP takes the "dominant" 
approach, and simulates water and energy fluxes using parameters of the dominant LCT. CLM4 (Lawrence et al., 2011; Jin \& Wen, 2012; added in WRF version 3.5) is the land component of the Community Earth System Model (CESM). CLM4 incorporates sophisticated treatment of geophysical and geochemical processes, and provides more complex parameterizations of surface characteristics and advanced estimations of water and energy fluxes. It employs a tilling approach that differentiates between five primary sub-grid LCTs (vegetated, urban, lake, wetland, and glacier). The vegetated portion within a grid cell is subsequently divided into patches of up to 4 of 16 plant functional types (PFTs), each prescribed with distinct parameters (Subin et al., 2011). The CLM4 PFTs are translated from the WRF input LCTs through a lookup table and are assigned to grid cells (Lu \& Kueppers, 2012).

\subsection{Forest loss in the Southeast Asian Massif}

Two one-way nested domains were designed in this study (Figure 1a). The outer domain has a coarse grid spacing of $25 \mathrm{~km}$, covering the Southeast Asia to capture the synoptic-scale features. The inner domain covers the SAM with a fine grid spacing of $5 \mathrm{~km}$. The highresolution satellite-based twenty-first-century forest cover product provided by Hansen et al. (2013) was used to generate the forest loss over the study area. The product describes forest cover in the year 2000 across the globe at $30 \mathrm{~m}$ spatial resolution and the forest loss or gain information in each pixel in the following years. It has been proven to have accurately captured the forest cover change in both highland and lowland areas over Southeast Asia (Zeng et al., 2018). The forest cover data in the year 2000 was aggregated into $5 \mathrm{~km} \times 5 \mathrm{~km}$ grids to match the WRF model grid spacing (Figure 1a), and was subsequently superimposed onto the original MODIS 30s land cover product to generate the control ("CTL") land cover scenario (Figure 1b).

The change of forest cover during the period 2000-2014 was also aggregated into $5 \mathrm{~km} \times 5$ $\mathrm{km}$ grids and then converted to areal percentages in each grid cell (Figure 2a). In the SAM, changes in forest cover occurred in $74.5 \%$ grid cells, leading to an areal mean deforestation of $2.26 \%$ (Figures $2 \mathrm{a}$ and $2 \mathrm{~b}$ ). Most of these grid cells experienced forest loss less than $10 \%$ (Figure 2c). Specifically, deforestation reached up to 10\% in the northern Thailand and northern Laos (highland), and in the northwest of Cambodia (lowland). Highland and lowland regions were distinguished based on an elevation threshold of $300 \mathrm{~m}$ (Figure 1b, Zeng et al., 2021). In the lowlands, agriculture could be intense throughout the entire year because of irrigation from reservoirs, lakes or rivers. Yet, crops in higher elevations are rain-fed and cannot benefit from irrigation during the dry season; the croplands thus become bare ground. Therefore, the forest cover change between 2000 and 2014 were superimposed onto the "CTL" scenario in two ways to represent the land cover scenario based on satellite-observed deforestation (hereafter "SIM" scenario). For grid cells experienced net forest losses, the percentage of cropland (bare ground) in lowland (highland) increased accordingly while the percentages of forest categories (i.e., evergreen broadleaf forest, deciduous broadleaf forest, and mixed forests in the study area) decreased proportionally. In contrast, for grid cells experienced net forest gain, the percentages of forest categories proportionally increased while the percentages of non-forest categories decreased. The fractions of LCTs ("LANDUSEF" parameter in the WRF model) were recalculated for both CTL and SIM scenarios.

\subsection{Experimental design}

The critical effect of subgrid-scale variability on simulated evapotranspiration response to deforestation can be quantified by comparing WRF simulations using the three LSSs, namely, 
Noah mosaic, CLM, and Noah-MP. For the Noah mosaic scheme, two $N$ values of 3 and 9 were adopted. $N=3$ is the default setting in the Noah mosaic scheme embedded in the WRF model. The most abundant three land cover types occupy more than $93 \%$ land area fractions in the inner domain. When the $N$ value is adjusted to 9 , the sum of land area fractions is nearly $100 \%$. Thus, four groups of simulations were conducted in this study, referred to as Mosaic3, Mosaic9, CLM, and NoahMP. Mosaic9 considered all LCTs at the subgrid-scale, while Mosaic3 only considered the first three land cover categories within each grid cell. CLM theoretically took the first four PFTs in the vegetated portion. NoahMP took the "dominant" approach. In each group, numerical experiments under two scenarios with and without the satellite-observed deforestation were performed. The difference between SIM and CTL scenarios represents the response of evapotranspiration to forest loss of the corresponding LSS. Besides, the model sensitivity of evapotranspiration response to forest loss can be assessed under the different settings of highland deforestation conversion (to bare ground) and lowland deforestation conversion (to cropland).

All numerical simulations shared the same physical options except for the difference in LSS or its land cover. Detailed physical schemes were summarized in Table 1 . The two nested domains had $220 \times 175$ and $190 \times 190$ horizontal grid cells respectively, with a downscaling ratio of 1:5 between the inner domain and its parent domain. 30 vertical levels extended from the surface to $100 \mathrm{hPa}$ were used in all simulations. The fifth-generation reanalysis (ERA5) of European Centre for Medium-Range Weather Forecasts (ECMWF) was adopted to provide initial and lateral boundary conditions for the simulations (Hersbach \& Dee, 2016). Sea surface temperatures in all simulations were also determined and updated from ERA5 data. The ERA5 product has a spatial resolution of $0.25^{\circ} \times 0.25^{\circ}$ and hourly temporal resolution. All experiments were taken during the local dry season from November $15^{\text {th }}$ in 2014 to March $1^{\text {st }}$ in 2015 to better isolate the signal of the deforestation-induced evapotranspiration feedbacks from large scale synoptic systems. The first 16 days of each model run were treated as spin-up period, and the period from December $1^{\text {st }}$ to February $28^{\text {th }}$ was used for validations and analyses.

Specifically, LAI parameters were updated for the SAM based on the AHI LAI/FPAR product (Chen et al., 2019) in this study (Table 2). LAI values of different LCTs are derived from look-up tables for the Noah mosaic scheme and the Noah-MP scheme in the WRF model. The former only use the maximum and minimum LAI values within a year while the latter use monthly LAI series to consider the vegetation phenology. For the CLM scheme, monthly LAI values are prescribed for each PFT.

\section{Results}

\subsection{Validation of land surface schemes}

Due to the lack of in-situ evapotranspiration observations in the study region, daily temperature and precipitation records from 125 Global Surface Summary of the Day (GSOD) stations (Figure 1b) were adopted as the reference to assess the overall skill of WRF simulations under the SIM scenario. Remarkably, all simulations yielded high correlations of daily mean temperature with the corresponding station observations $(\mathrm{R}=0.96 \sim 0.97, \mathrm{P}<0.01)$, implying that the WRF simulations reasonably capture the temporal variability of surface air temperature in the study area (Figure 3a). As for daily precipitation, all simulations replicated similar temporal fluctuations compared to ground observations, with correlation coefficients ranging from 0.62 to $0.68(\mathrm{P}<0.01)$, even though all schemes underestimated precipitation at the 
beginning of January and overestimated precipitation in the middle and at the end of February (Figure 3c).

The biases in different simulations varies distinctly, indicating that historical climate simulations over the SAM are highly sensitive to the use of LSSs. The large difference may mainly come from the different land-atmosphere interaction processes and parameterizations in these schemes. Mosaic3 and Mosaic9 produced fairly close results and evidently performed worse than the other two schemes. The noticeable deficiency for the Noah mosaic is the large bias of temperature $\left(-1.90^{\circ} \mathrm{C}\right.$, Figure $\left.3 \mathrm{~b}\right)$. The performances of the more sophisticated NoahMP are superior to those of Noah mosaic, with an average temperature bias of $-0.90{ }^{\circ} \mathrm{C}$ and precipitation bias of $-0.01 \mathrm{~mm}^{-1 a y^{-1}}$ (Figures $3 \mathrm{~b}$ and $3 \mathrm{~d}$ ). In general, CLM outperforms others with an average temperature bias of $-0.15^{\circ} \mathrm{C}$ and precipitation bias of $0.03 \mathrm{~mm}$ day $^{-1}$, illustrating the ability of CLM to realistically capture the surface energy balance and water vapor fluxes.

\subsection{Simulated responses of evapotranspiration to deforestation}

The choice of LSS also largely affects the simulated magnitude and pattern of how forest cover change impacts evapotranspiration over the region (Figure 4). The WRF model generally reproduces the deforestation-induced evapotranspiration decreases in all four groups of simulations. The mean evapotranspiration changes are up to -0.034 (95\% confidence interval [$0.038-0.030]) \mathrm{mm} \mathrm{day}^{-1}$ and -0.038 [-0.041 -0.034] $\mathrm{mm}^{-1 a y^{-1}}$ for Mosaic3 and Mosaic9, respectively, while the simulated decrease is only $-0.024[-0.026-0.020] \mathrm{mm}^{-1 a y^{-1}}$ and -0.020 [-0.022 - 0.018$] \mathrm{mm}^{-1} \mathrm{day}^{-1}$ for CLM and NoahMP, with the magnitude around half of that from the simulation with Noah mosaic. The greatest contrast among the four simulation groups roots in the spatial pattern of evapotranspiration response. With respect to the Noah mosaic scheme, decreases in evapotranspiration primarily occur in highland regions like northern Laos and northern Thailand, and lowland regions like northwest Cambodia (Figures 4a and 4b). This spatial pattern matches well with that of forest cover change (Figure 2a). In contrast, the decreases in evapotranspiration simulated by CLM and NoahMP are more heterogeneous, mainly originating from lowland regions like Cambodia and the southern Thailand (Figures $4 \mathrm{c}$ and $4 d)$.

In the framework of the WRF model, land surface parameters are primarily functions of LCTs at the grid level. Compared to the "mosaic/tiling" approach, the "dominant" approach tends to neglect the climate response to land cover changes that does not result in the conversions of dominant type. In the SAM, however, the dominant LCT had changed in only $2.0 \%$ grid cells, which discretely distributed over the study area (Figure 2). Specifically, there are many localized grid cells with high magnitude of evapotranspiration change from the WRF simulations using NoahMP (Figure 4d). Their locations are consistent with where the dominant LCT had changed (Figure 2a). Such a spatial pattern does not appear in the simulations with Noah mosaic, and is likely associated with the "dominant" approach for NoahMP scheme. Unexpectedly, the spatial pattern of evapotranspiration response and the locations of grids with high values for CLM were very similar to those of NoahMP (Figure 4c).

\subsection{Modelled sensitivity of evapotranspiration to forest loss}

Considering the remarkable differences in the spatial patterns of evapotranspiration response, we hypothesize that treatments of subgrid-scale variability among these LSSs play an important role in shaping the climate feedback of land cover change. Further analyses of the simulated evapotranspiration change at the gird level support the hypothesis (Figure 5). The 
sensitivity of Noah mosaic, in which subgrid-scale variability is considered, was consistent in all grid cells no matter their dominant LCT had changed or not. Taking highland grids as an example, the simulated evapotranspiration response by Mosaic 3 is $-0.22 \mathrm{~mm}^{\text {day }}{ }^{-1}(\mathrm{R}=-0.87$, $\mathrm{P}<0.01)$ and $-0.29 \mathrm{~mm} \mathrm{day}^{-1}(\mathrm{R}=-0.94, \mathrm{P}<0.01)$ per $10 \%$ forest loss in grids with the dominant LCT unchanged and changed, respectively (Figure 5a). For Mosaic9 simulations, the evapotranspiration response to forest loss is $-0.22 \mathrm{~mm}_{\text {day }}{ }^{-1} 10 \%{ }^{-1}(\mathrm{R}=-0.94, \mathrm{P}<0.01)$ and $0.26 \mathrm{~mm} \mathrm{day}^{-1} 10 \%{ }^{-1}(\mathrm{R}=-0.98, \mathrm{P}<0.01)$ in the two types of highland grid cells (Figure $5 \mathrm{~b}$ ). In lowland grid cells, the sensitivity of evapotranspiration change to forest loss is also similar among the two types for Mosaic3 and Mosaic9 schemes (black and blue lines in Figures 5a and $5 b)$.

In contrast, the relationship between evapotranspiration changes and forest losses is quite weak in the simulations with CLM and NoahMP at those grid cells that the dominant LCT did not change, displaying a large underestimation for the evapotranspiration response (yellow lines in Figures $5 \mathrm{c}$ and 5d). Nevertheless, the evapotranspiration reduction of CLM and NoahMP in highland grid cells with the dominant LCT changed is $-0.08 \mathrm{~mm}^{-1 a y^{-1}} 10 \%{ }^{-1}(\mathrm{R}=-0.25, \mathrm{P}<$ $0.01)$ and $-0.13 \mathrm{~mm}$ day $^{-1} 10 \%{ }^{-1}(\mathrm{R}=-0.43, \mathrm{P}<0.01)$, respectively. The results show low correlation coefficients and large overestimation in the magnitude of evapotranspiration change (red lines in Figures 5c and 5d). The low sensitivity and misestimation of evapotranspiration also exist in those lowland grids that experienced forest cover change (black and blue lines in Figures $5 \mathrm{c}$ and $5 \mathrm{~d}$ ). The remarkable differences suggest that both the CLM scheme and the NoahMP scheme failed to accurately capture the evapotranspiration response of deforestation.

Moreover, the sensitivities of evapotranspiration change to forest loss in the highlands and the lowlands are of different magnitudes for the Noah mosaic scheme. The simulated evapotranspiration reduction ranges from 0.22 to $0.29 \mathrm{~mm}^{-1} \mathrm{day}^{-1}$ for per $10 \%$ forest loss in the highlands, whereas only about $0.08 \mathrm{~mm} \mathrm{day}^{-1} 10 \%{ }^{-1}$ in the lowlands (Figures $5 \mathrm{a}$ and $5 \mathrm{~b}$ ). Such a discrepancy is due to the different experiment designs of land cover change. Actually, the percentage of forest loss were converted to bare ground (cropland) in highland (lowland) grids, according to the different irrigation availability during the dry season (Zeng et al., 2021). The contrasts of biophysical characteristics between bare ground and forest in highland grids are greater than that between cropland and forest in lowland grids (Table 2), leading to larger sensitivity of evapotranspiration reduction to deforestation over highlands. However, such a difference between highland grid cells and lowland grid cells in evapotranspiration response to deforestation is not captured by the CLM and NoahMP schemes (Figures 5c and 5d).

\section{Discussion and conclusions}

Simulations of historical climate variability and climate response to land cover change are both highly sensitive to the choice of LSSs. The former may mainly relate to the framework and parameterizations of schemes (Chen et al., 2014; Ma et al., 2020), while the latter is largely dependent on the subgrid-variability of the LSSs (Li et al., 2013). Our results show that large magnitude biases exist within the results of the Noah mosaic scheme for historical climate simulations. The poor performance of historical simulations for Noah scheme has also been reported by a few studies over other regions (Chen et al., 2014; Salamanca et al., 2018; Liu et al., 2019). In contrast, Ma et al. (2020) demonstrated that the latent heat flux could be well simulated by the Noah scheme compared to other LSSs. These results indicate that the performance of WRF LSSs varies with regions and simulation periods, raising doubts about the 
transferability of the findings. The sources of uncertainty for the WRF model could also come from the atmospheric forcing, other physical parameterizations, model resolution, land surface parameters, and soil conditions (Li et al., 2014; Pieri et al., 2015; Lin and Cheng, 2016). Thus, cautions should be paid when employing LSSs in modeling the climate over a specific region, and the schemes should be validated before the simulations of land-atmosphere flux exchanges.

Nonetheless, this study shows that only Noah mosaic scheme which employs the sub-grid approach is able to reasonably reproduce the response of evapotranspiration to deforestation (Figures 4 and 5). Despite the remaining uncertainties in the poor performance of historical simulations, this study recommends the application of the Noah mosaic scheme in climate feedback research of land cover conversion in the WRF modeling framework. Specifically, two numbers $(N=3$ and $N=9)$ of the most abundant land cover types within grid cells were adopted in the Noah mosaic simulations. Mosaic3 and Mosaic9 demonstrated similar performance in the model validations and evapotranspiration responses to deforestation, suggesting that the default setting of $N=3$ could yield most changes of the surface energy fluxes and atmospheric states. Even so, the two types of grid cells (the dominant LCT changed and unchanged) had closer sensitivity for the Mosaic9 simulations that contained all types of land cover conversions at the subgrid-scale, and their correlation coefficients were larger than those of Mosaic3 (Figures 5a and 5b).

CLM is in good agreement with the observed air temperature and precipitation and outperforms other schemes, illustrating that the CLM may capture the surface energy balance and water vapor fluxes more realistically due to its complex model structure and advanced parameterizations of surface characteristics ( $\mathrm{Lu} \&$ Kueppers, 2012; Jin \& Wen, 2012). Theoretically, the official release of CLM model, in which the tiling approach is used, considers five primary sub-grid LCTs and first four PFTs in the vegetated portion (Bonan et al., 2002), and thus should be more suitable for simulating the climate responses to land cover change. However, the results revealed that CLM is less sensitive to forest cover change in those grid cells where the dominant LCT did not change, and the performance is similar to that of the NoahMP. This consistency implies that the theoretical "tiling" approach of CLM was not active when it was coupled into WRF, and the CLM scheme takes the "dominant" approach instead (Skamarock et al., 2019).

This study highlights that LSSs taking the "dominant" approach can underestimate or overestimate the climate response to land cover change. For example, $72.5 \%$ land grid cells had experienced forest cover change but their dominant LCT did not change during 2000-2014 in the SAM (Figure $2 b$ ). The biophysical characteristics of these grid cells remained unchanged in the deforested scenario compared with those in the control scenario when using the "dominant" approach. Consequently, the climate feedbacks of forest loss/gain in these grid cells were neglected by the model. Besides, about $2.0 \%$ grid cells had undergone alteration of dominant LCT during the study period, and nearly $51.8 \%$ (66.1\%) of them experienced forest cover change that less than $10 \%(20 \%)$. Therefore, the climate response to slight changes of forest cover in these grid cells could be largely amplified in the "dominant" approach, which converts the dominant LCT and reforms the biophysical characteristics of the whole grid in the model. Furthermore, the "dominant" approach can be highly sensitive to the grid spacing of model since the representations of land cover categories are likely to change with the dominant LCT under different spatial resolution (Li et al., 2013; Mallard \& Spero, 2019). Taken $3 \mathrm{~km} \times 3 \mathrm{~km}$ 
grid spacing experiment design as an example, the proportion of forest cover changed grid cells with and without alteration of dominant LCT are $1.5 \%$ and $74.5 \%$ in the study area, respectively. The patchy forest cover changes in SAM show higher degree of spatial heterogeneity at the 3 $\mathrm{km}$ grid spacing, and the "dominant" approach could lack the representation of subgrid-scale interactions over more grid cells.

Due to the limited evapotranspiration observations in the SAM, the temperature and precipitation records from GSOD stations were used to validate the model performance. Further validations with extended observations and meteorological variables are still needed to perform comprehensive assessments and to acknowledge deficiencies of each LSS. Besides, only three most commonly used LSSs among the wide range of physical parameterized options in WRF were tested. Additional evaluations of other LSSs are desirable. Nevertheless, this study confirmed the critical role of subgrid-scale variability for WRF LSSs in the climate response simulations. The findings are anticipated to be broadly robust when transferring to other regions, other variables or other types of land cover change. Hence, future efforts for better representation of subgrid-scale variability in WRF LSSs are desirable as they will improve the capability in simulating the climate response to land cover change. One recommendation for WRF CLM that could improve the simulated climate response to deforestation is to correct the "tiling" approach in the code. The refined descriptions of land-atmosphere water and energy exchange in Noah mosaic scheme are also needed.

\section{Acknowledgments}

This study was supported by the National Natural Science Foundation of China (42071022, 42001321), the China Postdoctoral Science Foundation (2020M672693, 2021T140292), the start-up fund provided by the Southern University of Science and Technology (29/Y01296122), and Highlight Project on Water Security and Global Change of the Southern University of Science and Technology (G02296302). We thank the Center for Computational Science and Engineering at Southern University of Science and Technology for providing computing resources. We sincerely appreciate Dr. Zong-Liang Yang for his constructive comments on this paper.

\section{Conflict of interest}

The authors declare no competing interests.

\section{References}

Alkama, R., \& Cescatti, A. (2016). Biophysical climate impacts of recent changes in global forest cover. Science, 351(6273), 600-604. https://doi.org/10.1126/science.aac8083

Avissar, R. (1991). A statistical-dynamic approach to parameterize subgrid-scale land-surface heterogeneity in climate models. Surveys in Geophysics, 12(1-3), 155-178. https://doi.org/10.1007/Bf01903417

Avissar, R., \& Pielke, R. A. (1989). A parameterization of heterogeneous land surfaces for atmospheric numerical-models and its impact on regional meteorology. Monthly Weather Review, 117(10), 2113-2136. https://doi.org/10.1175/15200493(1989)117<2113:Apohls>2.0.Co;2

Betts, A. K. (2009). Land-surface-atmosphere coupling in observations and Models. Journal of Advances in Modeling Earth Systems, 1(3), 18 pp. https://doi.org/10.3894/james.2009.1.4 
Bonan, G. B. (2008). Forests and climate change: forcings, feedbacks, and the climate benefits of forests. Science, 320(5882), 1444-1449. https://doi.org/10.1126/science.1155121

Bonan, G. B., Oleson, K. W., Vertenstein, M., Levis, S., Zeng, X. B., Dai, Y. J., et al. (2002). The land surface climatology of the community land model coupled to the NCAR community climate model. Journal of Climate, 15(22), 3123-3149. https://doi.org/10.1175/1520-0442(2002)015<3123:tlscot>2.0.co;2

Bou-Zeid, E., Anderson, W., Katul, G. G., \& Mahrt, L. (2020). The Persistent Challenge of Surface Heterogeneity in Boundary-Layer Meteorology: A Review. Boundary-Layer Meteorology, 177, 227-245. https://doi.org/10.1007/s10546-020-00551-8

Chen, Y., Sun, K., Chen, C., Bai, T., Park, T., Wang, W., el al. (2019). Generation and Evaluation of LAI and FPAR Products from Himawari-8 Advanced Himawari Imager (AHI) Data. Remote Sensing, 11(13), 1517. https://doi.org/10.3390/rs11131517

Chen, F., \& Dudhia, J. (2001). Coupling an advanced land surface-hydrology model with the Penn State-NCAR MM5 modeling system. Part I: Model implementation and sensitivity. Monthly Weather Review, 129(4), 569-585. https://doi.org/10.1175/15200493(2001)129<0569:caalsh>2.0.co;2

Chen, F., Janjić, Z., \& Mitchell, K. (1997). Impact of Atmospheric Surface-layer Parameterizations in the new Land-surface Scheme of the NCEP Mesoscale Eta Model. Boundary-Layer Meteorology, 85(3), 391-421. https://doi.org/10.1023/a:1000531001463

Chen, F., Liu, C., Dudhia, J., \& Chen, M. (2014). A sensitivity study of high-resolution regional climate simulations to three land surface models over the western United States. Journal of Geophysical Research: Atmospheres, 119(12), 7271-7291. https://doi.org/10.1002/2014jd021827

Dudhia, J. (1989). Numerical Study of Convection Observed during the Winter Monsoon Experiment Using a Mesoscale Two-Dimensional Model. Journal of the Atmospheric Sciences, $\quad 46(20), \quad 3077-3107 . \quad$ https://doi.org/10.1175/15200469(1989)046<3077:nsocod>2.0.co;2

Ek, M. B. Mitchell, K. E., Lin, Y., Rogers, E., Grunmann, P., Koren, V., et al. (2003). Implementation of Noah land surface model advances in the National Centers for Environmental Prediction operational mesoscale Eta model. Journal of Geophysical Research, 108(D22). https://doi.org/10.1029/2002jd003296

Georgescu, M. (2015). Challenges Associated with Adaptation to Future Urban Expansion. Journal of Climate, 28(7), 2544-2563. https://doi.org/10.1175/jcli-d-14-00290.1

Giorgi, F., \& Avissar, R. (1997). Representation of heterogeneity effects in Earth system modeling: Experience from land surface modeling. Reviews of Geophysics, 35(4), 413-437. https://doi.org/10.1029/97rg01754

Hansen, M. C., Wang, L., Song, X.-P., Tyukavina, A., Turubanova, S., Potapov, P. V., \& Stehman, S. V. (2020). The fate of tropical forest fragments. Science Advances, 6(11), eaax8574. https://doi.org/10.1126/sciadv.aax8574

Hansen, M. C., Potapov, P. V., Moore, R., Hancher, M., Turubanova, S. A., Tyukavina, A., et al. (2013). High-Resolution Global Maps of 21st-Century Forest Cover Change. Science, 342(6160), 850-853. https://doi.org/10.1126/science.1244693

Hersbach, H. \& Dee, D. (2016). ERA5 reanalysis is in production. ECMWF Newsletter. 147, 7. 
Hong, S.-Y. \& Lim, J, (2006). The WRF single-moment 6-class microphysics scheme (WSM6). Asia-Pacific Journal of Atmospheric Sciences, 42, 129-151.

Hong, S.-Y., Noh, Y., \& Dudhia, J. (2006). A New Vertical Diffusion Package with an Explicit Treatment of Entrainment Processes. Monthly Weather Review, 134(9), 2318-2341. https://doi.org/10.1175/mwr3199.1

Jiménez, P. A., Dudhia, J., González-Rouco, J. F., Navarro, J., Montávez, J. P., \& GarcíaBustamante, E. (2012). A Revised Scheme for the WRF Surface Layer Formulation. Monthly Weather Review, 140(3), 898-918. https://doi.org/10.1175/mwr-d-11-00056.1

Jin, J., \& Wen, L. (2012). Evaluation of snowmelt simulation in the Weather Research and Forecasting model. Journal of Geophysical Research: Atmospheres, 117, D10110, https://doi.org/10.1029/2011jd016980

Jung, M., Reichstein, M., Ciais, P., Seneviratne, S. I., Sheffield, J., Goulden, M. L., et al. (2010). Recent decline in the global land evapotranspiration trend due to limited moisture supply. Nature, 467(7318), 951-954. https://doi.org/10.1038/nature09396

Kain, J. S. (2004). The Kain-Fritsch Convective Parameterization: An Update. Journal of Applied Meteorology, 43(1), 170-181. https://doi.org/10.1175/15200450(2004)043<0170:tkcpau>2.0.co;2

Koster, R. D., \& Suarez, M. J. (1992). A Comparative Analysis of Two Land Surface Heterogeneity Representations. Journal of Climate, 5(12), 1379-1390. https://doi.org/10.1175/1520-0442(1992)005<1379:acaotl>2.0.co;2

Lawrence, D., \& Vandecar, K. (2015). Effects of tropical deforestation on climate and agriculture. Nature Climate Change, 5(1), 27-36. https://doi.org/10.1038/nclimate2430

Lawrence, D. M., Oleson, K. W., Flanner, M. G., Thornton, P. E., Swenson, S. C., Lawrence, P. J., et al. (2011). Parameterization improvements and functional and structural advances in Version 4 of the Community Land Model. Journal of Advances in Modeling Earth Systems, 3(3). M03001. https://doi.org/10.1029/2011ms000045

Li, M., Song, Y., Huang, X., Li, J., Mao, Y., Zhu, T., et al. (2014). Improving mesoscale modeling using satellite-derived land surface parameters in the Pearl River Delta region, China. Journal of Geophysical Research: Atmospheres, 119(11), 6325-6346. https://doi.org/10.1002/2014jd021871

Li, D., Bou-Zeid, E., Barlage, M., Chen, F., \& Smith, J. A. (2013). Development and evaluation of a mosaic approach in the WRF-Noah framework. Journal of Geophysical Research: Atmospheres, 118(21), 11,918-11,935. https://doi.org/10.1002/2013jd020657

Lin, T. S., \& Cheng, F. Y. (2016). Impact of Soil Moisture Initialization and Soil Texture on Simulated Land-Atmosphere Interaction in Taiwan. Journal of Hydrometeorology, 17(5), 1337-1355. https://doi.org/10.1175/jhm-d-15-0024.1Liu, L., Ma, Y., Menenti, M., Zhang, X., \& Ma, W. (2019). Evaluation of WRF modeling in relation to different land surface schemes and initial and boundary conditions: a snow event simulation over the Tibetan Plateau. Journal of Geophysical Research: Atmospheres. 124, 209-226. https://doi.org/10.1029/2018jd029208

Lu, Y., \& Kueppers, L. M. (2012). Surface energy partitioning over four dominant vegetation types across the United States in a coupled regional climate model (Weather Research and Forecasting Model 3-Community Land Model 3.5). Journal of Geophysical Research: Atmospheres, 117, D06111. https://doi.org/10.1029/2011jd016991 
Niu, G.-Y., Yang, Z.-L., Mitchell, K. E., Chen, F., Ek, M. B., Barlage, M., et al. (2011). The community Noah land surface model with multiparameterization options (Noah-MP): 1. Model description and evaluation with local-scale measurements. Journal of Geophysical Research, 116, D12109. https://doi.org/10.1029/2010jd015139

Ma, S., Zhou, L., Fei, L., \& Zhu, J. (2019). Evaluation of WRF land surface schemes in landatmosphere exchange simulations over grassland in Southeast Tibet. Atmospheric Research, 234, 104739. https://doi.org/10.1016/j.atmosres.2019.104739

Mahmood, R., Pielke, R. A., Hubbard, K. G., Niyogi, D., Dirmeyer, P. A., McAlpine, C., et al. (2013). Land cover changes and their biogeophysical effects on climate. International Journal of Climatology, 34(4), 929-953. https://doi.org/10.1002/joc.3736

Mallard, M. S., \& Spero, T. L. (2019). Effects of mosaic land use on dynamically downscaled WRF simulations of the contiguous United States. Journal of Geophysical Research: Atmospheres, 124, 9117-9140. https://doi.org/10.1029/2018JD029755

Mlawer, E. J., Taubman, S. J., Brown, P. D., Iacono, M. J., \& Clough, S. A. (1997). Radiative transfer for inhomogeneous atmospheres: RRTM, a validated correlated-k model for the longwave. Journal of Geophysical Research: Atmospheres, 102(D14), 16663-16682. https://doi.org/10.1029/97jd00237

Noilhan, J., \& Planton, S. (1989). A Simple Parameterization of Land Surface Processes for Meteorological Models. Monthly Weather Review, 117(3), 536-549. https://doi.org/10.1175/1520-0493(1989)117<0536:aspols>2.0.co;2

Pieri, A. B., von Hardenberg, J., Parodi, A., \& Provenzale, A. (2015). Sensitivity of Precipitation Statistics to Resolution, Microphysics, and Convective Parameterization: A Case Study with the High-Resolution WRF Climate Model over Europe. Journal of Hydrometeorology, 16(4), 1857-1872. https://doi.org/10.1175/jhm-d-14-0221.1

Salamanca, F., Zhang, Y., Barlage, M., Chen, F., Mahalov, A., \& Miao, S. (2018). Evaluation of the WRF-Urban Modeling System Coupled to Noah and Noah-MP Land Surface Models Over a Semiarid Urban Environment. Journal of Geophysical Research: Atmospheres, 123(5), 2387-2408. https://doi.org/10.1002/2018jd028377

Sellers, P. (1991). Modeling and observing land-surface-atmosphere interactions on large scales. Surveys in Geophysics, 12, 85-114.

Skamarock, W. C. et al. (2019). A Description of the Advanced Research WRF Version 4. NCAR Tech. Note NCAR/TN-556+STR. 145 pp.

Subin, Z. M., Riley, W. J., Jin, J., Christianson, D. S., Torn, M. S., \& Kueppers, L. M. (2011). Ecosystem Feedbacks to Climate Change in California: Development, Testing, and Analysis Using a Coupled Regional Atmosphere and Land Surface Model (WRF3CLM3.5). Earth Interactions, 15(15), 1-38. https://doi.org/10.1175/2010ei331.1

Tomasi, E., Giovannini, L., Zardi, D., \& de Franceschi, M. (2017). Optimization of Noah and Noah_MP WRF Land Surface Schemes in Snow-Melting Conditions over Complex Terrain. Monthly Weather Review, 145, 4727-4745. https://doi.org/10.1175/MWR-D-16-0408.1

Yang, Z.-L., Niu, G. Y., Mitchell, K. E., Chen, F., Ek, M. B., Barlage, M., et al. (2011). The community Noah land surface model with multiparameterization options (Noah-MP): 2. Evaluation over global river basins. Journal of Geophysical Research, 116(D12), D12110. https://doi.org/10.1029/2010jd015140 
Yano, J. I. (2016). Subgrid-scale physical parameterization in atmospheric modeling: How can we make it consistent? Journal of Physics A: Mathematical and Theoretical, 49(28), 284001. https://doi.org/10.1088/1751-8113/49/28/284001

Zeng, Z. Z., Estes, L., Ziegler, A. D., Chen, A. P., Searchinger, T., Hua, F. Y., et al. (2018). Highland cropland expansion and forest loss in Southeast Asia in the twenty-first century. Nature Geoscience, 11, 556-562. https://doi.org/10.1038/s41561-018-0166-9

Zeng, Z. Z., Wang, D. S., Yang, L., Wu J., Ziegler, A. D., Liu, M. F., et al. (2021). Deforestation-induced warming over tropical mountain regions regulated by elevation. Nature Geoscience, 14, 23-29. https://doi.org/10.1038/s41561-020-00666-0 
Table 1. The physical parameterization schemes used in this study.

\begin{tabular}{ll}
\hline Physics option & \multicolumn{1}{c}{ Parameterization scheme } \\
\hline Microphysics & WSM 6-class scheme (Hong and Lim 2006) \\
Longwave radiation & RRTM scheme (Mlawer et al 1997) \\
Shortwave radiation & Dudhia scheme (Dudhia 1989) \\
Planetary Boundary Layer & YSU scheme (Hong et al 2006) \\
Cumulus & Kain-Fritsch scheme (Kain 2004) \\
Surface layer & Revised MM5 Monin-Obukhov scheme (Jimenez et al 2012) \\
\hline
\end{tabular}


Table 2. The updated LAI parameters of different land cover types over the Southeast Asian Massif.

\begin{tabular}{|c|c|c|c|c|c|c|c|c|c|c|c|c|c|c|c|}
\hline \multirow{2}{*}{ ID } & \multirow{2}{*}{ Land cover type } & \multicolumn{12}{|c|}{ Noah-MP / CLM } & \multicolumn{2}{|c|}{ Noah mosaic } \\
\hline & & Jan & Feb & Mar & Apr & May & Jun & Jul & Aug & Sep & Oct & Nov & Dec & Maximum & Minimum \\
\hline 2 & $\begin{array}{c}\text { Evergreen Broadleaf } \\
\text { Forest }\end{array}$ & 5.12 & 4.83 & 4.94 & 5.53 & 5.41 & 5.71 & 5.50 & 5.78 & 5.92 & 5.81 & 5.44 & 5.32 & 5.92 & 4.83 \\
\hline 4 & $\begin{array}{c}\text { Deciduous Broadleaf } \\
\text { Forest }\end{array}$ & 1.48 & 0.85 & 0.71 & 1.32 & 1.50 & 3.35 & 4.03 & 3.25 & 3.67 & 3.41 & 2.87 & 2.36 & 4.03 & 0.71 \\
\hline 5 & Mixed Forests & 3.33 & 2.79 & 2.30 & 2.31 & 2.63 & 4.44 & 4.61 & 5.23 & 4.89 & 4.72 & 4.17 & 3.80 & 5.23 & 2.30 \\
\hline 6 & Closed Shrublands & 0.26 & 0.26 & 0.31 & 0.41 & 0.63 & 0.82 & 0.82 & 0.67 & 0.41 & 0.31 & 0.26 & 0.26 & 0.82 & 0.26 \\
\hline 7 & Open Shrublands & 0.54 & 0.58 & 0.62 & 0.75 & 1.05 & 1.55 & 1.68 & 1.13 & 0.75 & 0.62 & 0.58 & 0.54 & 1.68 & 0.54 \\
\hline 8 & Woody Savanas & 1.75 & 1.22 & 1.18 & 1.92 & 1.87 & 3.00 & 2.66 & 3.32 & 3.61 & 3.48 & 2.77 & 2.27 & 3.61 & 1.18 \\
\hline 9 & Savanas & 1.26 & 1.07 & 1.11 & 1.64 & 1.72 & 2.44 & 2.20 & 2.45 & 2.55 & 2.46 & 2.01 & 1.68 & 2.55 & 1.07 \\
\hline 10 & Grasslands & 0.77 & 0.73 & 0.75 & 0.88 & 0.91 & 1.02 & 0.98 & 1.07 & 1.19 & 1.18 & 1.01 & 0.88 & 1.19 & 0.73 \\
\hline 11 & Permanent Wetlands & 1.21 & 1.13 & 1.23 & 1.50 & 1.36 & 1.49 & 1.21 & 1.19 & 1.40 & 1.44 & 1.33 & 1.35 & 1.50 & 1.13 \\
\hline 12 & Croplands & 0.64 & 0.60 & 0.60 & 0.70 & 0.74 & 0.92 & 0.88 & 1.03 & 1.17 & 1.22 & 0.98 & 0.76 & 1.22 & 0.60 \\
\hline 14 & $\begin{array}{l}\text { Cropland/Natural } \\
\text { Vegetation Mosaic }\end{array}$ & 1.11 & 1.03 & 0.77 & 1.19 & 1.63 & 1.81 & 1.67 & 1.62 & 1.62 & 1.58 & 1.31 & 1.06 & 1.81 & 0.77 \\
\hline 16 & $\begin{array}{c}\text { Barren or Sparsely } \\
\text { Vegetated }\end{array}$ & 0.35 & 0.33 & 0.36 & 0.43 & 0.29 & 0.31 & 0.25 & 0.75 & 0.81 & 0.73 & 0.41 & 0.22 & 0.81 & 0.22 \\
\hline
\end{tabular}


Figure 1. Study area and land cover type. (a) Two-nested WRF simulation domains and the spatial patterns of satellite-observed forest cover in the year 2000. (b) The dominant land cover type ("LU_INDEX" parameter) of the CTL land cover scenario over the study area. Land cover types are defined by the Noah-modified 20-category International Geosphere-Biosphere Programme (IGBP) land cover classifications. The corresponding land cover type of each ID is listed in table 2. Blue triangles denote the locations of 125 in-situ GSOD weather stations. Plus symbols represent highland areas (elevation $\geq 300 \mathrm{~m}$ ).
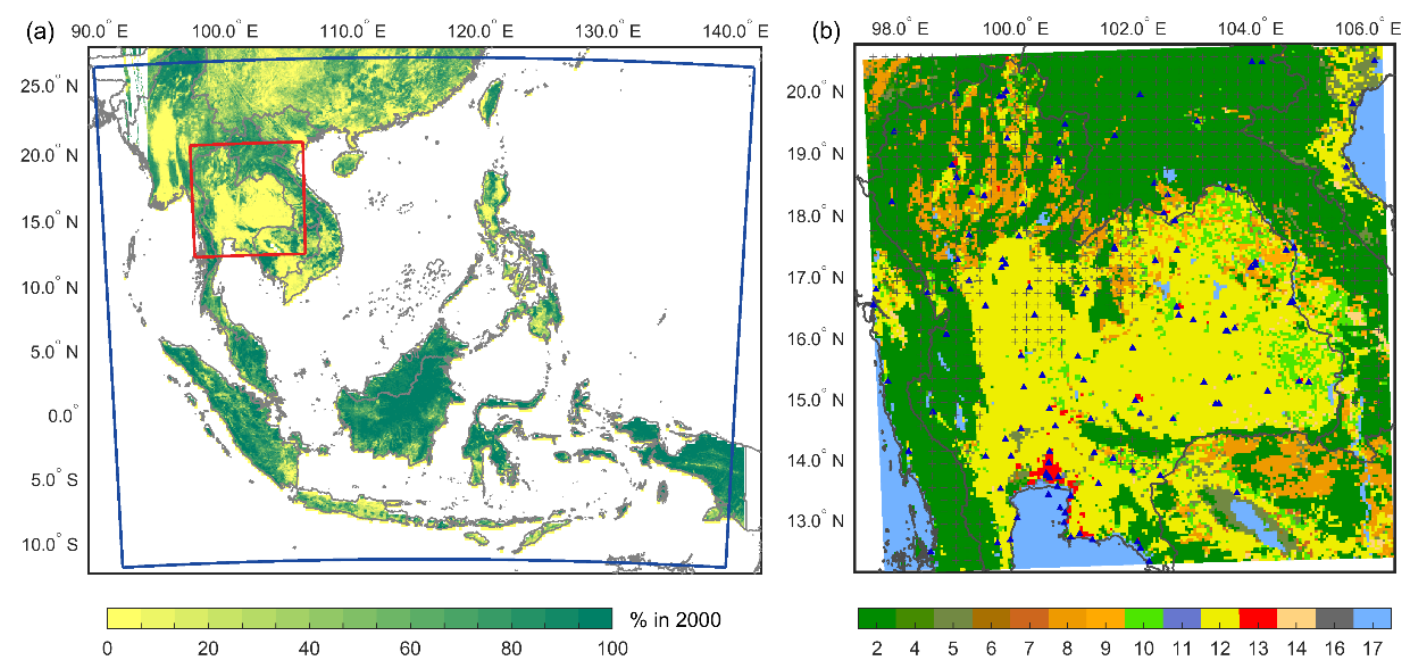
Figure 2. Satellite-observed forest cover change. (a) Spatial pattern of the forest cover change (brown: forest loss; green: forest gain) during the period 2000-2014 over the study area, and the locations of the grids of which the dominant land cover type had changed (blue symbols). (b) Components of the $5 \mathrm{~km} \times 5 \mathrm{~km}$ land grids that divided based on their variation in forest cover change. (c) Relative frequency of grids with different forest loss intervals.
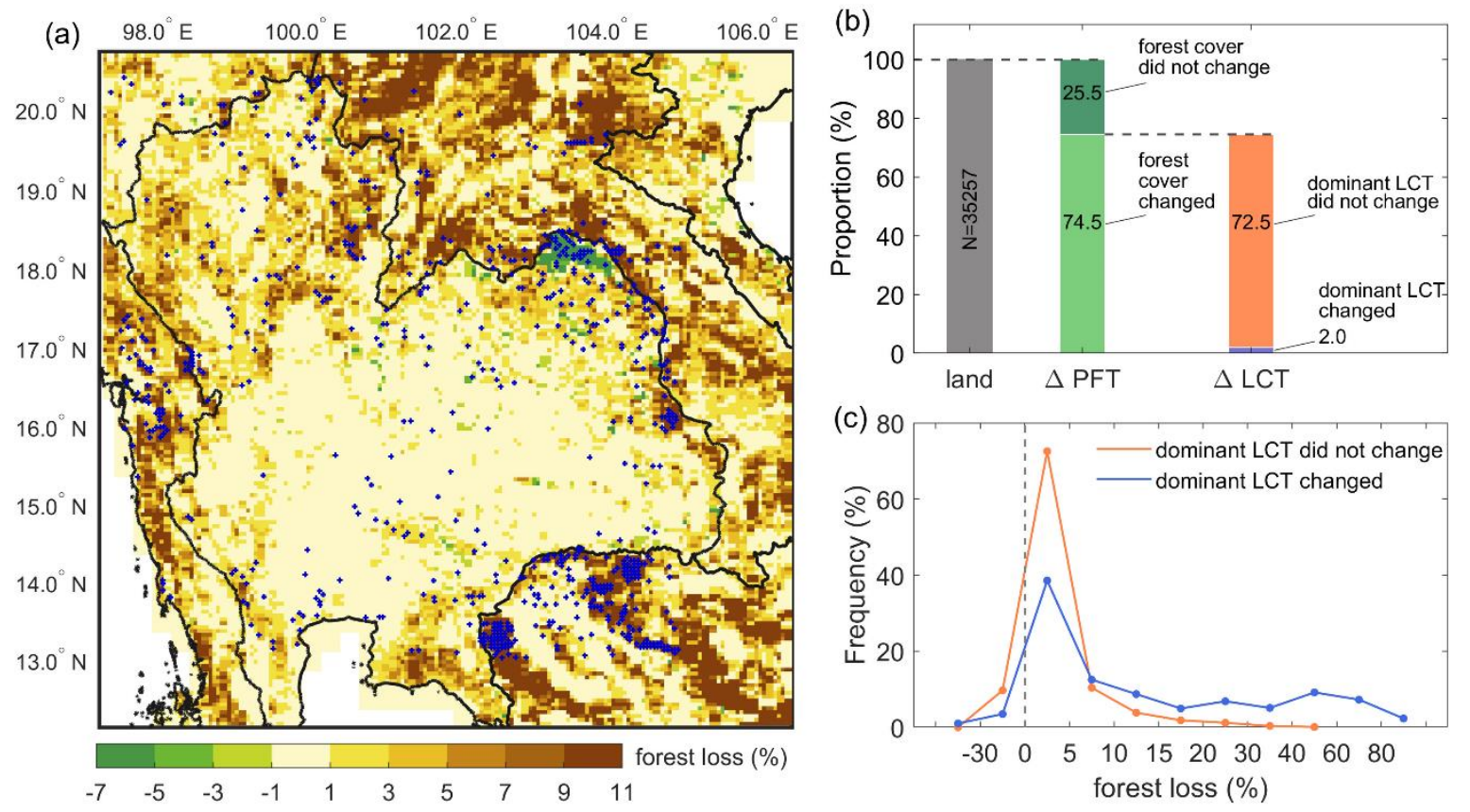
Figure 3. Validation of the model simulations. (a, c) Daily series of the mean air temperature and mean precipitation averaged over the GSOD stations and the results of WRF simulations using different land surface schemes under the SIM scenario. (b, d) Biases of daily mean temperature and precipitation between the SIM simulations and GSOD data during the study period. Error bars show the $95 \%$ confidence interval of the bias.
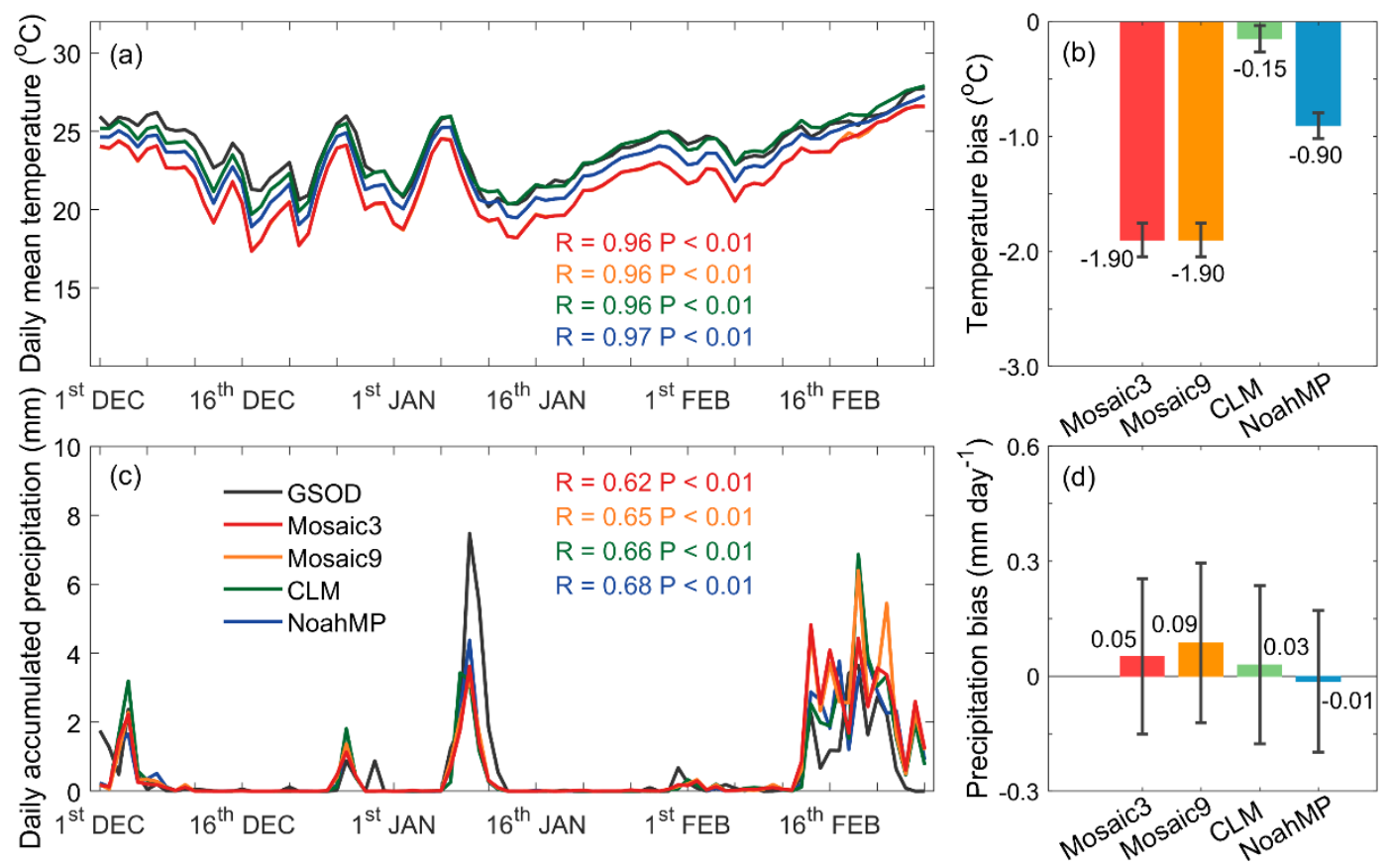
Figure 4. Simulated evapotranspiration change induced by the satellite-observed deforestation (SIM minus CTL) using the (a) Mosaic3, (b) Mosaic9, (c) CLM, and (d) NoahMP land surface schemes.
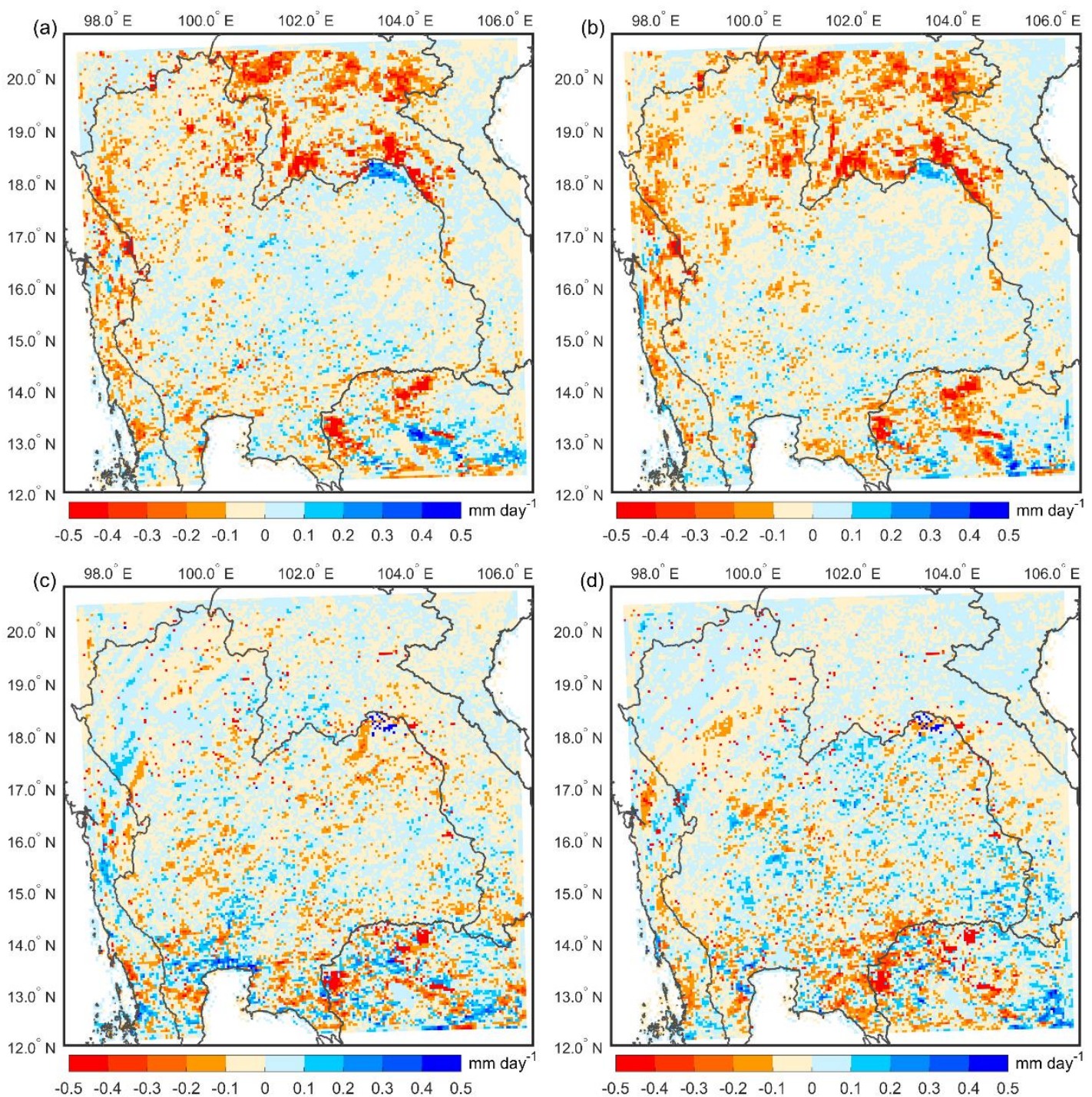
Figure 5. Sensitivity of the simulated evapotranspiration change (SIM minus CTL) to forest loss at the gird level using the (a) Mosaic3, (b) Mosaic9, (c) CLM, and (d) NoahMP land surface schemes. Grids experienced forest loss were divided into four types based on their variation in dominant land cover type $(\triangle \mathrm{LCT}=0$ : dominant land cover type did not change; $\Delta \mathrm{LCT} \neq 0$ : dominant land cover type changed) and their elevation (lowland or highland). For deforested grid cells within each of the four types, change in evapotranspiration was regressed versus the forest loss fraction by using the ordinary least squares regression.
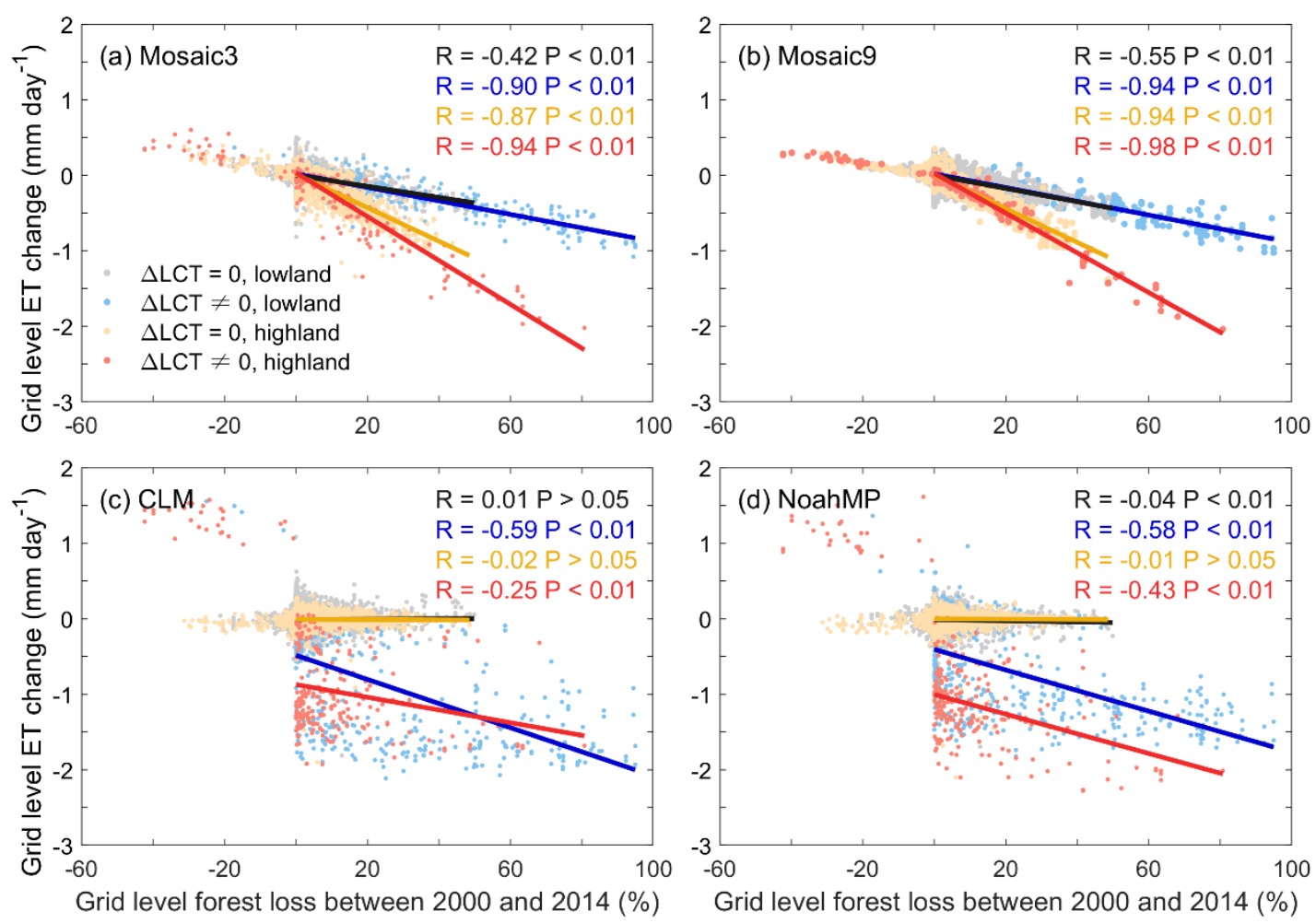